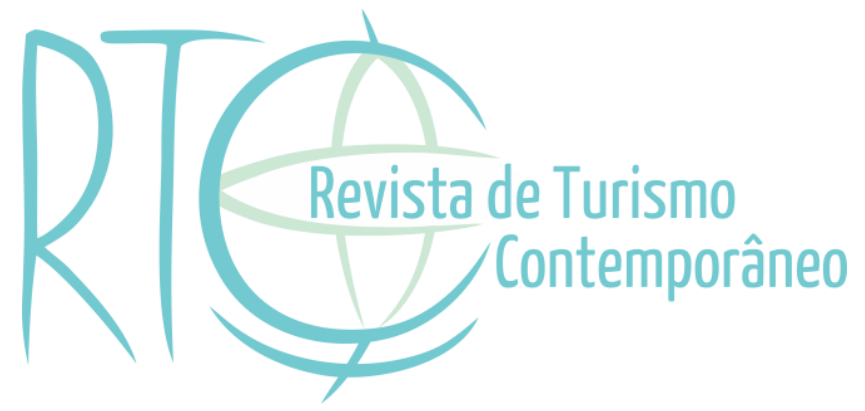

\title{
A percepção dos gestores de lojas de souvenirs do atrativo turístico Maria Fumaça- Região Uva e Vinho,
} RS

The perception of the managers of souvenir shops of the tourism attraction Maria Fumaça - Uva e Vinho Region, RS

\section{Tauana Macedo de Paula}

Mestre em Turismo e Hospitalidade da Universidade de Caxias do Sul-UCS, Caxias do Sul/RS, Brasil.

E-mail: tathamacedo@gmail.com

Silvio Luiz Gonçalves Vianna

Professor adjunto do Mestrado em Turismo e Hospitalidade da Universidade de Caxias do Sul- UCS, Caxias do Sul/ RS, Brasil.

E-mail: svianna77@gmail.com 


\section{RESUMO}

Tendo em vista a importância do souvenir para o turismo, uma vez que transmite a cultura do lugar e tangibiliza a experiência que o turista vivencia na localidade, buscou-se analisar como este produto está sendo disponibilizado aos turistas. Neste sentido, este artigo investiga a eficiênciada disposição espacial do comércio de souvenirs do atrativo turístico "Maria Fumaça", localizado na Serra Gaúcha (RS), cujo percurso abrange os municípios de Bento Gonçalves, Garibaldi e Carlos Barbosa. Para alcançar este objetivo, foi elaborado um estudo de caso que deu origem a uma pesquisa exploratória com abordagem quantitativa, aplicada a partir de questionários, nos quais foi utilizada a escala Likert de concordância. Os instrumentos de pesquisa foram direcionados aos responsáveis pelas lojas, os quais foram inquiridos quanto aos quesitos localização e fluxo de clientes em suas lojas. Como principal conclusão do estudo verificou-se que os estabelecimentos se encontram em uma posição privilegiada, devendo, porém, avaliar melhor o perfil do cliente desejado e também estabelecer um planejamento que esteja relacionado à eficiência dos empreendimentos.

Palavras-chave: Turismo. Souvenir. Ponto de distribuição. "Maria Fumaça". Serra Gaúcha (RS).

\section{ABSTRACT}

Given the importance of souvenir for tourism, as it conveys the culture of the place and makes tangible the experience that the tourist experiences in the locality, we attempted to analyze how this product is being made available to tourists. Thus, this paper investigates the efficiency of the spatial arrangement of the souvenir shops of tourist attraction "Maria Fumaça", located in Serra Gaúcha (RS), whose route covers the cities of Bento Gonçalves, Garibaldi and Carlos Barbosa. To accomplish this, a case study was developed which led to an exploratory research with quantitative approach, applied from questionnaires in which we used the Likert scale of agreement. The research instruments were directed to those responsible for stores, which were asked questions about the location and customer traffic in their stores. As a main conclusion of the study it was found that the establishments are in a privileged position, must, however, to assess the profile of the desired client and also establish a plan that is related to increase the efficiency of projects.

Keywords: Tourism. Souvenir. Distribution Point. "Maria Fumaça”. Serra Gaúcha (RS). 


\section{INTRODUÇÃO}

A aquisição de souvenirs está amplamente presente no turismo. Nesse tipo de consumo os turistas procuram tornar mais concretas e, também, eternizar as experiências vividas através do turismo. "Souvenires são um componente essencial e um significante eloquente da experiência de viagem no mundo contemporâneo" (Freire-Medeiros \& Castro, 2007: 35).

Esses produtos são importantes, pois representam, em parte, os modos e costumes de uma comunidade, fazendo com que o turista tenha contato com uma cultura diferente da sua. Desta maneira, esses elementos fazem "[...] o elo entre duas culturas distintas - a do visitante e a do nativo" (Reis, 2008: 7).

Sendo assim, esses elementos fazem o papel promocional do destino turístico ao qual se refere. Já que quando destinados a familiares e/ou amigos podem despertar nesses o desejo de conhecer o local (Horodyski, Manosso \& Gândara, 2012).

Partindo deste pressuposto, torna-se fundamental analisar os souvenirs sob a ótica do espaço turístico, pois, entende-se que para haver um maior consumo desses objetos eles devem estar localizados em lugares com maior incidência de turistas, ou seja, próximo aos atrativos turísticos. Além de possuírem infraestrutura adequada para receber os mesmos, bem como um planejamento que organize e monitore administrativamente o estabelecimento.

Para tanto, é necessário que esta análise prime pelos princípios do mix de marketing, mais precisamente pela categoria ponto de distribuição que trata do local onde o produto/serviço está sendo comercializado. Esta característica é determinante no momento do consumo, em especial do consumo de souvenirs em destinos turísticos. Neste sentido, é possível verificar de acordo com os estudos de Leite, Fiates e Lima (2013) que a localização pode ser um dos principais fatores para a construção de uma vantagem competitiva que fortaleça o desempenho de determinado negócio.

É importante destacar que o ato de consumir não envolve somente uma prática material envolvendo a troca de um valor monetário por um bem ou serviço, trata-se de uma produção de significados, tal como aborda Lipovetsky (2007). Desta forma, segundo as pesquisas de Baudrillard (2008), os espaços de consumo são, atualmente, ambientes nos quais pode-se desfrutar de opções de lazer e servem também para ampliar o convívio familiar, o que permite que se satisfaçam por meio do consumo. Assim verifica-se que a localização 
adequada pode facilitar aos consumidores o acesso à satisfação das mais variadas necessidades.

Para compreender melhor de que maneira se desenvolve este fenômeno, o presente artigo tem como objetivo principal analisar a eficiência da disposição espacial do comércio de souvenirs em cada uma das estações do trem "Maria Fumaça". Entende-se que este atrativo turístico ${ }^{1}$ seja de grande relevância para a região da Uva e Vinho da Serra Gaúcha (RS), o que o caracteriza como um estudo de caso exploratório com abordagem quantitativa. Visando a obtenção dos dados foram aplicados questionários, elaborados com base na escala Likert de concordância, junto aos proprietários de duas lojas de souvenirs localizadas no percusso do atrativo turístico "Maria Fumaça", localizado na Serra Gaúcha (RS), ou seja, em Bento Gonçalves e Carlos Barbosa ${ }^{2}$.

O presente estudo inicia com esta introdução que apresenta o tema escolhido para a pesquisa, bem como mostra de maneira sucinta a metodologia de desenvolvimento da pesquisa e os objetivos do mesmo. Na sequência o artigo traz algumas considerações teóricas sobre souvenir e pontos de distribuição, passando para a apresentação do local onde a pesquisa foi realizada. Em seguida são expostos os dados levantados, que foram analisados por meio de quadros e das observações feitas pelos pesquisadores em campo. Por fim, são apresentadas as considerações finais sobre a pesquisa e as sugestões para futuros estudos.

\section{O CONSUMO DE SOUVENIRS E SUA RELAÇÃO COM O TURISMO}

Apesar de alguns autores considerarem o souvenir como um objeto sem uma utilidade aparente, é fato, que esses produtos estão presentes em todo o âmbito turístico. Uma pesquisa de 2012 do Ministério do Turismo [Mtur] (2014a) constatou que o turista brasileiro, em viagens pelo país, gasta em média 12,7\% em compras. Como exemplo desse consumo a pesquisa destaca os artesanatos de Caruaru (PE), os chocolates de Gramado (RS), entre outros produtos. Assim, é possível considerar esses elementos como souvenirs, e constatar que, pelo seu consumo, possuem interesse para quem os adquire (Horodyski, Manosso \& Gândara,

\footnotetext{
${ }^{1}$ Para o Ministério do Turismo - Mtur, atrativo turístico é todo lugar, objeto ou acontecimento de interesse para o turismo (Embratur, 1992)."[...] todo elemento material que tem a capacidade própria, ou em combinação com outros, para atrair visitantes de uma determinada localidade ou zona" (Cerro, 1992). Disponível em: $<$ http://www.dadosefatos.turismo.gov.br/dadosefatos/espaco_academico/glossario/detalhe/A.html >. Acesso em: 12 ago 2014.

${ }^{2}$ Cabe salientar que a estação do atrativo turístico "Maria Fumaça" localizada em Garibaldi não possui loja de souvenir.
} 
2013). Esses objetos, ao contrário de algumas opiniões, possuem um valor intangível que ultrapassa o econômico, pois “[...] ocupam o papel de representantes simbólicos da cultura do outro" (Reis, 2008: 2).

A origem da palavra souvenir é francesa e significa a ação de lembrar (Machado \& Siqueira, 2008). Dessa forma, os souvenirs podem ser considerados como um meio para relembrar momentos vividos com o outro (Collins-Kreiner \& Zins, 2011). Sua origem remete a acontecimentos da história, como o Grand Tour, onde os viajantes demonstravam interesse pela cultura local por meio da coleta de relíquias. $\mathrm{Na}$ ocasião, as pessoas levavam para suas casas gravuras de ruínas (que podem ser consideradas como souvenir), feitas por artistas locais, com o intuito de recordar a viagem (Salgueiro, 2002).

Ainda que a projeção da fantasia pudesse estar presente, turistas queriam levar para casa, ao retornarem, imagens que pudessem documentar para si mesmos e para seus amigos e parentes, sua estada em um determinado local; que fossem, enfim, registros de memória (idem: 305, grifo nosso).

Segundo Gordon (1986) há vários tipos de elementos que podem ser considerados souvenirs, dentre eles destacam-se: produtos da comunidade local (por exemplo, artesanato e alimentos); artigos que representam o destino turístico através das imagens (por exemplo, cartões postais); objetos em seu estado natural (por exemplo, conchas); elementos que indiquem a marca do local (por exemplo, imãs); produtos que traduzam os elementos principais do destino turístico (por exemplo, réplica do Cristo Redentor ou da Torre Eifel).

Cabe salientar que, geralmente, a produção e comercialização desses objetos estão baseadas na sustentabilidade, uma vez que gera emprego e renda para a comunidade local, utilizando-se de técnias e matérias-primas artesanais e habilidades pessoais. Além de ser um meio competitivo para introduzir a localidade no turismo mundial (Escalona, 2006).

Tendo em vista os aspectos da sociedade globalizada de hoje, o consumo está ligado mais às questões subjetivas do que materiais. Assim, o sujeito acaba consumindo os valores intangíveis transmitidos através das experiências.

A cultura do consumo abrange todo um conjunto de imagens, símbolos, valores e atitudes que se desenvolveram com a Modernidade, que se tornaram positivamente associadas ao consumo (real ou imaginário) de mercadorias e que passaram a orientar pensamentos, sentimentos e comportamentos de segmentos crescentes da população do chamado Mundo Ocidental (Taschner, 2000: 39). 
Diante dessa ótica, o consumo do souvenir, no turismo, se estabelece através da necessidade de tangibilizar a experiência vivida nas viagens, pois esses objetos são considerados "signos e/ou símbolos" de um povo (Machado \& Siqueira, 2008: 8). Esse tipo de consumo baseia-se no emocional (Torres, García \& Pulido-Fernàndez, 2013). "Os objetos adquiridos nas lojas de souvenirs atuam ainda na ressignificação de expectativas e imaginários anteriores à viagem, na medida em que proporcionam o contato com elementos sintetizadores da cultura local, atribuindo-lhe concretude [...]" (Reis, 2008: 6). Dessa forma, o consumo de souvenirs se torna uma maneira de mediar e construir sentidos na relação do turista com a comunidade local (Machado \& Siqueira, 2008).

Contudo, para que esse consumo se consolide de uma forma satisfatória e prazeiroza para o turista é importante analisar os pontos em que estão localizados os estabelecimentos encarregados do comércio dos souvenirs. O ideal seria que esses produtos estivessem perto dos atrativos turísticos, pois assim, despertaria no turista, uma motivação maior para o seu consumo (Horodyski, Manosso \& Gândara, 2013). Dessa forma, é pertinente analisar o comércio de souvenir a partir do viés dos pontos de distribuição.

\section{PONTOS DE DISTRIBUIÇÃO NO TURISMO}

O marketing é a área de conhecimento dentro de uma organização que se dedica a identificar e a satisfazer as necessidades e desejos dos clientes. Sua função primordial é criar um relacionamento vantajoso com o cliente (Kotler \& Armstrong, 2007). Com isso, esse modelo de marketing, que procura conhecer a fundo o cliente, tem sua orientação dirigida para o viés do consumidor (Las Casas, 2008).

Dentro das concepções de marketing para produtos e serviços está o mix de marketing, que é composto por 4 Ps (produto, preço, praça e promoção), o que poderá ser observado na figura 1. Para Kotler e Armstrong (2007:42), o "mix de marketing" ou composto de marketing envolve um conjunto de ferramentas que é utilizado para fazer com que os clientes tenham seu interesse despertado para a compra de um produto ou serviço, o que pode ser corroborado por meio da afirmação feita feita pelos autores de que: "O mix de marketing é o conjunto de ferramentas de marketing táticas e controláveis que a empresa combina para produzir a resposta que deseja no mercado-alvo. Consiste em tudo o que a empresa pode fazer para influenciar a demanda de seu produto". 
Figura 1. Os 4 Ps do mix de marketing

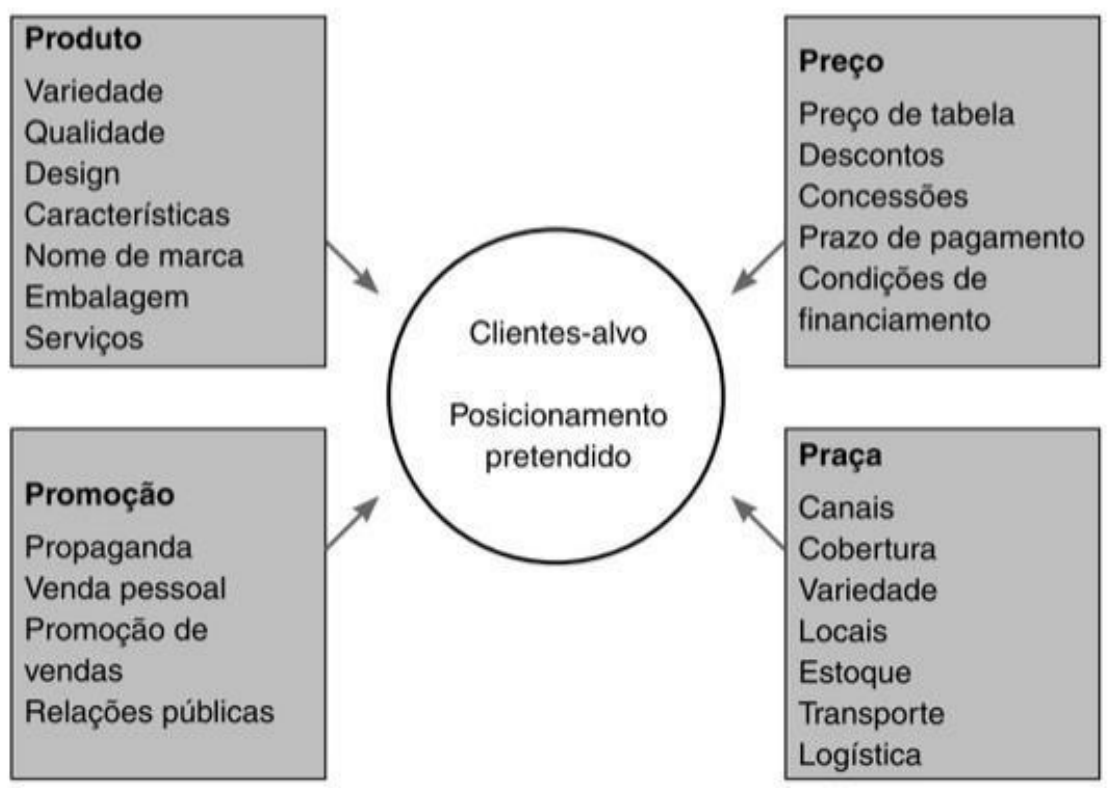

Fonte: Kotler e Armstrong (2007: 42).

Assim, cada um dos 4 Ps pode ser caracterizado de maneira específica, uma vez que são compostos por um conjunto de procedimentos e atividades que de acordo com os estudos de Magalhães e Sampaio (2007: 34) podem ser descritos da seguinte forma:

O produto é a formatação do produto ou do serviço em si. O preço é o esforço exigido do consumidor final. O ponto [ou praça] é a distribuição, o local de venda e de disponibilização do produto ou serviço. A promoção é o conjunto de elementos de divulgação, propagação e promoção.

No turismo essas estratégias de marketing também devem ser aplicadas com o intuito de disponibilizar um serviço satisfatório para o turista. Diante disso, o foco deste estudo será o "P" de praça, ou ponto de distribuição.

Uma característica marcante do ponto de distribuição no turismo é a questão do deslocamento. Pois no ambiente industrial, geralmente, o produto vai até o cliente, já no turismo ocorre o contrário, tendo em vista que é o turista que precisa se deslocar até o atrativo turístico (Dias \& Cassar, 2005). Isso acontece devido a uma particularidade do turismo, que é inerente a qualquer prestação de serviço: a inseparabilidade, na qual a produção e o consumo acontecem simultaneamente, o desempenho do serviço depende tanto do produtor, quanto do turista e o consumo ocorre no local onde está sendo ofertado o serviço turístico (Middleton, 2002). "O turista sai desse intercâmbio com algo tangível (por exemplo, um souvenir) ou intangível (o prazer de um passeio)” (Petrocchi, 2004: 39). 
Dias e Cassar (2005) afirmam que os pontos de distribuição no turismo devem ser planejados não só quanto ao local para aonde o turista está se dirigindo, mas sim, durante todo o percurso, prevendo paradas, quando o trajeto for longo, para que a viagem seja confortável.

Os mesmos autores também abordam a importância da realização de algumas paradas estratégicas para a compra de souvenirs, destacando a importância desses elementos para a experiência turística:

O planejamento de roteiros turísticos passando por locais de aquisição de peças de artesanato típicas do local - ou mesmo de suvenires que venham a gerar recordações ao turista - não demonstra ser somente uma atividade econômica necessária ao local turístico, mas, também, uma ferramenta a mais para garantir uma experiência integral positiva da viagem. As lembranças físicas podem, ainda, auxiliar no retorno daquele turista, bem como apoiar a propaganda do tipo "boca-a-boca" em torno da apreciação de peças típicas do local visitado (idem: 212).

A localização correta dos estabelecimentos que oferecem os produtos turísticos é fundamental para o sucesso dos empreendimentos. Assim, é essencial que haja um conhecimento prévio de onde estão localizados os consumidores (turistas) e quais são as suas preferências (Dias \& Cassar, 2005).

Tal situação abrange, também, o comércio dos souvenirs, pois estes estabelecimentos devem estar concentrados onde há um grande fluxo de turistas, ou seja, no perímetro onde estão localizados os atrativos turísticos (Horodyski, Manosso \& Gândara, 2013).

Dias e Cassar (2005) afirmam que o turista só terá contato com o produto turístico se houver uma distribuição do mesmo satisfatória, ou seja, o produto turístico deve estar disponível no local e no tempo determinados pela demanda.

Com isso, percebendo a importância do souvenir no âmbito turístico, o qual poderá transmitir ao turista lembranças da experiência vivenciada, bem como servir de presente para amigos e/ou familiares, julga-se importante analisar onde o mesmo está sendo comercializado. Se está sendo disponibilizado para o turista de uma maneira facilitada, não só em termos do produto em si, mas também na questão do local em que se encontra. Por exemplo: se tem acesso para pessoas com alguma dificuldade de locomoção, se atende as demandas do turista estrangeiro, se possui planejamento de vendas, entre outros quesitos. 


\section{MÉTODO DA PESQUISA}

Esta pesquisa caraceteriza-se, pelos seus objetivos, como exploratória, cujas informações são obtidas na fonte do objeto de estudo. A peça chave desse tipo de pesquisa é a coleta de dados, na qual é possível obter características políticas, sociais, e econômicas de determinada população (Cervo, Bervian \& Silva, 2007).

Já quanto aos seus procedimentos, trata-se de um estudo de caso que permite a identificação ampla das características de determinado objeto (Gil, 2007). Podendo ser definido "[...] como um conjunto de dados que descrevem uma fase ou a totalidade do processo social de uma unidade [...]" (Diehl \& Tatim, 2004: 61).

Caracteríza-se, também, quanto à abordagem do seu problema, como uma pesquisa quantitativa, onde a preocupação está centrada na quantificação dos dados coletados, com o intuito de mostrar a visão dos principais envolvidos em relação à sua concordância com a ocorrência do conjunto de indicadores escolhidos para a avaliação dos empreendimentos.

O instrumento utilizado para a coleta dos dados foi o questionário. Esse tipo de instrumento possibilita maior exatidão nas respostas. As suas questões possuem uma lógica e tem como centro um assunto específico (Diehl \& Tatim, 2004). As afirmações que serviram de base para a construção do questionário foram elaboradas conforme a Escala Likert, na qual utilizou-se o grau de concondância, onde nos pontos extremos encontravam-se as respostas discordo totalmente e concordo totalmente.

A vantagem em se utilizar esse tipo de escala é que "[...] as categorias são utilizadas em uma ordem lógica e o entrevistado seleciona as que melhor descrevem suas reações" (Shiraishi, 2012: 57). Foram atribuídos valores para cada grau de concordância com a finalidade de serem avaliados analiticamente. Ficando assim: concordo totalmente: 5; concordo: 4; nem concordo, nem discordo: 3; discordo: 2; discordo totalmente:1.

Assim, as variáveis e os indicadores que serviram de base para esta pesquisa pode ser visualidas no quando 1 .

Quadro 1 - Variáveis e indicadores para a análise da localização das lojas de souvenir do atritivo turístico "Maria Fumaça"/RS.

\begin{tabular}{|l|c|l|}
\hline \multicolumn{1}{|c|}{ Variáveis } & Indicadores & \multicolumn{1}{c|}{ Objetivo } \\
\hline \multirow{3}{*}{ Localização } & Acesso & $\begin{array}{l}\text { Verificar se o acesso às lojas de souvenir é adequado. } \\
\text { Verificar se a visualização das lojas de souvenir é } \\
\text { satisfatória. }\end{array}$ \\
& Visualização & $\begin{array}{l}\text { Verificar se as lojas de souvenir possuem acesso para } \\
\text { PNE. }\end{array}$ \\
\hline Vendas & Quantidade de produtos & Verificar se a quantidade de produtos vendidos nas \\
\hline
\end{tabular}




\begin{tabular}{|c|c|c|}
\hline & $\begin{array}{l}\text { vendidos } \\
\text { Meta de vendas } \\
\text { Expectativa de preço }\end{array}$ & $\begin{array}{l}\text { lojas de souvenir está sendo satisfatória. } \\
\text { Verificar se as lojas de souvenir possuem uma meta } \\
\text { de vendas. } \\
\text { Verificar se as lojas de souvenir possuem uma meta } \\
\text { de vendas em termos de preço. }\end{array}$ \\
\hline Fluxo de clientes & Quantidade de clientes & $\begin{array}{l}\text { Verificar se o fluxo de clientes nas lojas de souvenir } \\
\text { está atendendo as expectativas. }\end{array}$ \\
\hline Faturamento & $\begin{array}{l}\text { Receita prevista } \\
\text { Receita efetiva } \\
\text { Moeda }\end{array}$ & $\begin{array}{l}\text { Verificar se é feita uma previsão de receitas mensal } \\
\text { para as empresas. } \\
\text { Verificar se é gerado um relatório mensal de vendas } \\
\text { efetuadas pelas empresas. } \\
\text { Verificar se as empresas estão preparadas para receber } \\
\text { em moeda estrangeira }\end{array}$ \\
\hline Perfil dos clientes & $\begin{array}{l}\text { Faixa etária } \\
\text { Gênero } \\
\text { Origem } \\
\text { Grau de instrução }\end{array}$ & $\begin{array}{l}\text { Verificar se é dada preferência a uma faixa etária } \\
\text { especifica de clientes nas lojas. } \\
\text { Verificar se é dada preferência a um gênero } \\
\text { específico de clientes nas lojas. } \\
\text { Verificar se é dada preferência a clientes de outras } \\
\text { cidades nas lojas. } \\
\text { Verificar se é dada preferência a clientes com grau de } \\
\text { instrução específico nas lojas. }\end{array}$ \\
\hline $\begin{array}{l}\text { Estratégia para } \\
\text { vendas }\end{array}$ & $\begin{array}{l}\text { Preço } \\
\text { Qualidade } \\
\text { Exclusividade }\end{array}$ & $\begin{array}{l}\text { Verificar se o principal diferencial das lojas é o } \\
\text { preço mais acessível. } \\
\text { Verificar se o principal diferencial das lojas é a } \\
\text { qualidade dos produtos. } \\
\text { Verificar se o principal diferencial das lojas é a } \\
\text { exclusividade dos produtos. }\end{array}$ \\
\hline
\end{tabular}

Fonte: Elaboração dos autores, com base nos estudos de Dias e Cassar (2005), Kotler e Armstrong (2007), Dornelas (2008) e Horodyski, Manosso e Gândara (2013).

Essas variáveis e indicadores foram escolhidos a partir da revisão bibliográfica feita nesse estudo. Os resultados serão apresentados por meio de quadros que demonstram a concordância dos empreendedores com as afirmações feitas de acordo com a escala apresentada nesta seção.

\section{CARACTERIZAÇÃO DO PONTO DE DISTRIBUIÇÃO DOS SOUVENIRS}

Os pontos de distribuição de souvenirs escolhidos para esta análise foram aqueles localizados no percurso do passeio de trem "Maria Fumaça" que percorre a região "Uva e Vinho" da Serra Gaúcha. Esse atrativo turístico engloba três cidades, Bento Gonçalves Garibaldi - Carlos Barbosa. Em duas estações onde o trem realiza as paradas estão as lojas de souvenirs.

O atrativo turístico "Maria Fumaça” teve início em 1993 percorrendo o sentido de Bento Gonçalves - Garibaldi - Carlos Barbosa. Atualmente, há a opção de percorrê-lo também no sentido contrário. A duração média do passeio é de duas horas totalizando um 
trajeto de 23 quilômetros. A operação do atrativo turístico fica a cargo da agência de viagens Giordani Turismo, sediada em Bento Gonçalves (Debenetti, 2006).

A locomotiva utilizada no passeio é do século XIX, conforme figura 2, composta por seis carros e funciona através do vapor produzido pela queima da lenha ou do carvão mineral em contato com a água (Debenetti, 2006), o que permite aos visitantes um contato com uma tecnologia que não é mais tão utilizada atualmente, principalmente nos meios de transporte, devido sua ineficiência energética e sua demanda por recursos naturais ${ }^{3}$.

Figura 2- Locomotiva "Maria Fumaça"

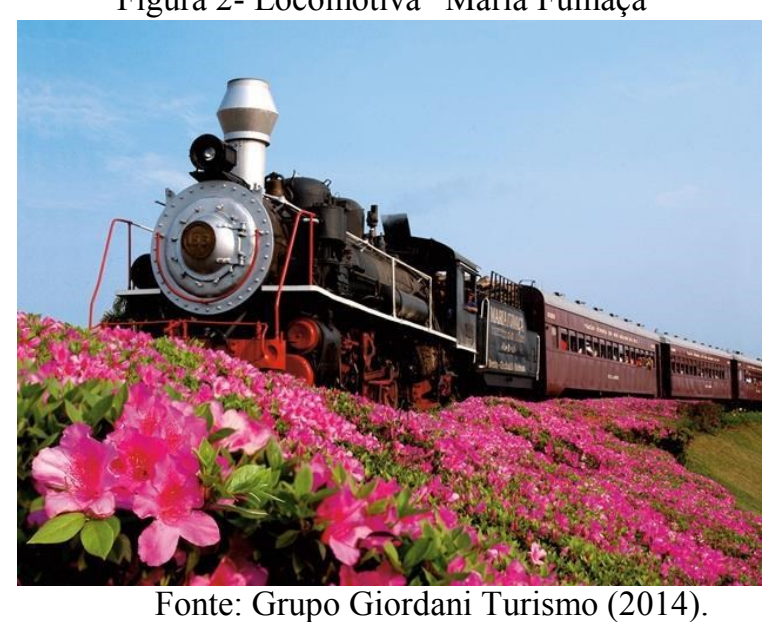

Nesse passeio, os turistas têm a oportunidade de entrar em contato com a cultura italiana, típica da região, através das manifestações culturais e da gastronomia. Dentro da locomotiva são realizadas apresentações como teatro e música e nas estações de Bento Gonçalves e Garibaldi são proporcionadas degustações dos produtos da região como o vinho, o queijo e o champanha (Debenetti, 2006).

\section{ANÁLISE DOS DADOS}

Em relação a primeira variável, localização, foram feitas perguntas sobre acesso, visualização e acesso para PNE. O objetivo era verificar se o acesso permitia um bom fluxo de turistas; se o estabelecimento encontrava-se em local de fácil visualização e ainda se no local onde as lojas estavam instaladas havia a possibilidade de acesso para portadores de

\footnotetext{
${ }^{3}$ Cabe destacar que a agência responsável pelo passeio possui a ISO 14001, que diz respeito à gestão ambiental. Com isso, apresenta um programa de gestão ambiental que comtempla o controle do consumo de lenha na locomotiva, o controle no consumo de água tratada, o controle na geração de resíduos, a limpeza do trecho ferroviário, entre outros cuidados com o meio ambiente (Grupo Giordani Turismo, 2013).
} 
necessidades especiais. Os resultados obtidos junto aos proprietários de cada uma das lojas podem ser observados no quadro 2.

Quadro 2 - Análise da variável localização

\begin{tabular}{|l|c|c|}
\hline Indicadores & Carlos Barbosa & Bento Gonçalves \\
\hline Acesso & 5 & 5 \\
\hline Visualização & 5 & 4 \\
\hline Acesso PNE & 4 & 5 \\
\hline
\end{tabular}

Fonte: elaboração dos autores (2014)

O quadro 2 mostra que na visão dos empreendedores a localização das lojas de souvenir é satisfatória, pois ambas são de fácil acesso, estão localizadas em áreas de visualização previlegiada e possibilitam o acesso à pessoas Portadores de Necessidades Especiais. Cabe salientar que elas se encontram próximas à estação do atrativo turístico "Maria Fumaça". Esse aspecto é considerado por Horodyski, Manoso e Gândara (2013: 131) de grande importância.

Notamos a importância da aproximação deste tipo de comércio com os espaços de maior fluxo de visitantes, e a motivação para o consumo destes produtos pode ter um significado maior quando consumido onde o turista experiencia o espaço turístico.

De acordo com as observações feitas no momento da aplicação dos instrumentos de pesquisa, foi possível constatar que a visão dos empreendedores corresponde à realidade e que os aspectos referentes à localização pesquisados favorecem a melhoria de desempenho dos estabelecimentos, por permitirem que se desperte a curiosidade dos visitantes, bem como seu livre trânsito, facilitando a visualização dos produtos oferecidos.

O quadro 3 está relacionado com a variável vendas, a qual apresenta a análise de aspectos como a quantidade de produtos vendidos; avalia a existência de uma meta de vendas em termos de quantidade de produtos e ainda se os proprietários dos estabelecimentos estipulam uma meta de vendas em termos de preço.

Quadro 3 - Análise da variável vendas

\begin{tabular}{|l|c|c|}
\hline \multicolumn{1}{|c|}{ Indicadores } & Carlos Barbosa & Bento Gonçalves \\
\hline Quantidade de produtos vendidos & 5 & 4 \\
\hline Meta de vendas - quantidade & 1 & 4 \\
\hline Meta de vendas - preço & 1 & 4 \\
\hline
\end{tabular}

Fonte: elaboração dos autores (2014) 
Conforme pode ser observado, por meio do quadro 3, as lojas de Carlos Barbosa e Bento Gonçalves concordam no aspecto quantidade de produtos vendidos, pois ambas consideram que as expectativas relacionadas com essa questão são satisfatórias. No entanto, apenas a loja de Bento Gonçalves possui metas na questão de quantidade de vendas e preço, o que aponta para a necessidade de que a loja de Carlos Barbosa desenvolva um planejamento que contemple essas informações, uma vez que pode estar tendo um desempenho inferior à sua real capacidade de negócios.

Kotler e Armstrong (2007) corroboram esta análise ao afirmarem em seus estudos que a definição de metas claras permite aos empreendimentos trabalhar no máximo de sua capacidade, oferecendo aos gestores a possibilidade de constatar periodicamente como está o nível de vendas, tanto em termos de quantidade, quanto em relação ao volume financeiro.

A variável que buscava analisar como está o fluxo de clientes gerou apenas uma afirmação, por isso não foi elaborado um quadro. $O$ intuito desta indagação era o de verificar se o fluxo de clientes estava de acordo com o previsto. As respostas foram "concordo totalmente" por parte da loja de Carlos Barbosa e "concordo" por parte da loja de Bento Gonçalves. Com isso, percebe-se que o fluxo de clientes está sendo satisfatório para ambas as lojas.

Essa constatação deve-se pelo fato de que as lojas se encontram próximas ao atrativo turístico. Segundo Horodyski, Manosso e Gândara (2013: 139) “[...] a oferta de souvenirs é influenciada pela demanda. Este tipo de comércio localiza-se aonde existe fluxo de turistas, pois o consumo destes bens ocorre no local de visitação".

Sobre a variável faturamento as afirmações tinham por objetivo analisar a existência de previsão de receitas mensais, a elaboração de um relatório mensal de vendas e também quanto à possibilidade de recebimento em moeda estrangeira, o que poderá ser verificado por meio do quadro 4.

Quadro 4 - Análise da variável faturamento.

\begin{tabular}{|l|c|c|}
\hline \multicolumn{1}{|c|}{ Indicadores } & Carlos Barbosa & Bento Gonçalves \\
\hline Previsão mensal de receitas para a empresa & 1 & 4 \\
\hline Relatório mensal de vendas & 1 & 5 \\
\hline Moeda estrangeira & 5 & 4 \\
\hline
\end{tabular}

Fonte: elaboração dos autores (2014).

O quadro 4 que visa analisar a variável faturamento mostra que por um lado a loja de Bento Gonçalves é mais organizada, pois possui previsão mensal de receitas e gera um relatório mensal de vendas. No entanto, essa loja parece não se importar tanto com o recebimento de moedas estrangeiras, ponto que difere da loja de Carlos Barbosa que apontou estar apta para trabalhar com moeda estrangeira. 
Segundo Dornelas (2008: 131) “[...] o empreendedor deve estabelecer quais são as metas financeiras de seu negócio e, por meio de instrumentos financeiros, acompanhar seu êxito". Tal posicionamento mostra que o estabelecimento de Bento Gonçalves está em vantagem, pois poderá estabelecer e cumprir metas financeiras que venham a ser estipuladas, bem como corrigi-las caso seja necessário.

Para viabilizar a análise da variável perfil dos clientes, as afirmações buscavam verificar a existência de preferência por uma faixa etária específica, preferência por um gênero específico, preferência por clientes de outras cidades e a preferência por clientes com um grau de instrução específico. As respostas podem ser visualizadas no quadro 5.

Quadro 5 - Análise da veriável perfil dos clientes.

\begin{tabular}{|c|c|c|}
\hline Indicadores & Carlos Barbosa & Bento Gonçalves \\
\hline Preferência quanto à faixa etária & 1 & 2 \\
\hline Preferência quanto ao gênero & 1 & 2 \\
\hline Preferência por clientes de outras cidades & 1 & 2 \\
\hline Preferência quanto ao grau de instrução & 1 & 1 \\
\hline
\end{tabular}

Fonte: elaboração dos autores (2014).

No marketing, conhecer o cliente é fundamental para conseguir realizar de forma positiva os seus desejos e as suas necessidades. Assim, percebe-se que as lojas de souvenir, conforme apresentado no quadro 5, não têm preferência por um tipo de público específico. No entanto, cabe ressaltar que seria importante que as mesmas realizassem uma pesquisa para diagnosticar o tipo de clientes que mais frequentam o estabelecimento, com a finalidade de estarem aptas a atender melhor os seus anseios. Esse tipo de estratégia é definida no marketing como orientação voltada para o cliente, na qual é valorizado o conhecimento sobre o seu consumidor (Kotler \& Amstrong, 2007).

No entanto, na observação feita em campo, foi possível constatar a amplitude de perfis de cliente que frequentam os estabelecimentos, o que dificulta a adoção de uma estratégia mais específica que venha a facilitar o atendimento das necessidades e anseios dos mesmos, uma vez que não se sabe qual será o perfil do próximo grupo que adentrará em cada um dos empreendimentos.

A variável estratégia de vendas abordou os seguintes aspectos: preço acessível como diferencial da loja; exclusividade dos produtos como diferencial da loja; qualidade dos produtos como diferencial da loja. O objetivo desta análise era verificar qual o tipo de estratégia era adotada por cada um dos empreendimentos pesquisados. Os resultados podem ser observados no quadro 6. 


\begin{tabular}{|l|c|c|} 
Quadro 6 - Análise da variável estratégia de vendas. \\
\begin{tabular}{|l|c|c|}
\hline Indicadores & Carlos Barbosa & Bento Gonçalves \\
\hline O diferencial é o preço acessível & 5 & 4 \\
\hline O diferencial é a exclusividade & 5 & 5 \\
\hline O diferencial é a qualidade & 5 & 5 \\
\hline
\end{tabular}
\end{tabular}

Fonte: elaboração dos autores (2014).

Nota-se, de acordo com o exposto no quadro 6, que as duas lojas concordam na relação preço e exclusividade como diferenciais. Como também, com relação à qualidade de seus produtos, tendo em vista que ambas relataram que este quesito é um de seus atributos. A questão preço acessível advém de itens que possum pouco valor monetário agregado como, por exemplo, ímãs de geladeira. O quesito exclusividade pode ser observado no artesanato, uma vez que ambas as lojas possuem produtos fabricados por artesãos que retratam a cultura local de uma forma única. A qualidade pode ser atribuída pela escolha do produtor dos souvenirs.

De acordo com a observação de campo feita pelos pesquisadores, foi possível constatar que o principal diferencial oferecido pelas lojas de souvenirs do atrativo "Maria Fumaça" é a exclusividade de seu artesanato, que busca aproveitar o trem como mote central de suas peças, o que acaba distinguindo-o de outros produtos oferecidos em lojas de artesanato da região.

\section{CONSIDERAÇÕES FINAIS}

A pesquisa conseguiu responder ao seu objetivo principal que foi analisar a eficiência da disposição espacial do comércio de souvenirs em cada uma das estações do trem "Maria Fumaça" que possuem loja de souvenirs. Quanto a localização, ambas encontram-se em áreas próximas ao atrativo principal, são visíveis e de fácil acesso. Isso estimula os turistas a entrar e consumir.

Tendo em vista que o atrativo turístico "Maria Fumaça" tem uma procura grande na maioria das épocas do ano é visto que o fluxo de turistas nas lojas de souvenir seria intenso. Atendendo as expectativas de vendas dos proprietários.

Percebe-se que os produtos característicos da região conferem às lojas uma exclusividade. Tendo em vista que os bens feitos artesanalmente configuram uma personalidade que, quase, não pode ser copiada.

\footnotetext{
${ }^{4}$ Em conversa informal com o responsável pela loja de souvenir de Carlos Barbosa obteve-se a informação de que, geralmente, o trem transporta em torno de trezentos passageiros em cada trajeto.
} 
Um aspecto que pede mais atenção é a deficiência no planejamento da loja de Carlos Barbosa que não estabelece metas de quantidade de produtos vendidos e de quanto quer receber mensalmente com a venda dos mesmos, isso pode trazer dificuldades para a correta gestão do empreendimento, uma vez que esses elementos são fundamentais para o controle do desempenho do negócio.

A questão da definição do perfil dos clientes é importante, porém é pouco explorada em ambos os empreendimentos, pois afeta outras variáveis apresentadas nesse trabalho como a quantidade de produtos vendidos. Detectando o público alvo do estabelecimento fica mais fácil atender as suas necessidades e desejos, o que pode contribuir de maneira significativa no incremento das vendas.

Tendo em vista que se trata de uma loja de souvenir localizada próximo a um atrativo turístico renomado, situado em um dos sessenta e cinco destinos indutores do turismo brasileiro $^{5}$ (Brasil, 2014b) acredita-se que a grande aposta seria em objetos que de fato caracterizassem a cultura da região, para que os turistas levassem um pouco da Serra Gaúcha para casa.

Deixa-se como sugestão para futuros estudos a necessidade de saber se há um perfil específico de cliente que usufrui do atrativo "Maria Fumaça", com o intuito de melhor atender suas expectativas e desejos no que tange ao consumo de souvenirs. Isso também auxiliaria num melhor retorno para os estabelecimentos existentes.

\footnotetext{
${ }^{5}$ Segundo o Ministério do Turismo, os destinos indutores do desenvolvimento turístico regional são aqueles que possuem infraestrutura básica e turística e atrativos qualificados, que se caracterizam como núcleo receptor e/ou distribuidor de fluxos turísticos (Brasil, 2014b).
} 


\section{REFERÊNCIAS}

Baudrillard, J. A. (2008). Sociedade de Consumo. Lisboa: edições 70.

Brasil. Ministério do Turismo. (2014a). Compras impulsionam o turismo doméstico. Recuperado em 06 de agosto, 2014, de: http://www.turismo.gov.br/turismo/noticias/todas_noticias/20140806.html

Brasil. Ministério do Turismo. (2014b). Relatório dos 65 destinos indutores. Recuperado em 22 de outubro, 2014, de http://www.turismo.gov.br/export/sites/default/turismo/o_ministerio/publicacoes/downloads publicacoes/65_destinos_indutores.pdf

Cervo, A. L, Bervian, P. A \& Silva, R. (2007). Metodologia científica. (6a Ed.) São Paulo: Pearson Pretince Hall.

COllins-Kreiner, N.\& Zins, Y. (2011). Tourist and souvenirs: changes through time, space and meaning. Journal of Heritage Tourism 6(1), 17-27, Recuperado em 15 de Agosto, 2014, de: DOI: $10.1080 / 1743873 X .2010 .515312$

Debenetti, V. E. S. (2006). Passeio de Trem Maria Fumaça: os diferentes olhares. Dissertação de Mestrado, Universidade de Caxias do Sul, RS, Brasil. Recuperado em 02 de junho, 2014, de https://www.ucs.br/site/pos-graduacao/formacaostrictosensu/turismo/dissertacoes/turismo-tede/?id=73

Dias, R.\& Cassar, M. (2005). Fundamentos do marketing turístico. São Paulo: Pearson Prentice Hall.

Diehl, A. A. \& Tatim, D. C. (2004). Pesquisa em ciências sociais aplicadas: métodos e técnicas. São Paulo: Prentice Hall.

Dornelas, J. C. A. (2008). Empreendedorismo - transformando ideias em negócios. (3a Ed). Rio de Janeiro: Elsevier.

Escalona, E. G. (2006). De la reliquia al souvenir. Revista de Filología Románica, 4, 399-408. $\begin{array}{lllll}\text { Recuperado em } & 19 \text { de } & \text { agosto, }\end{array}$ http://revistas.ucm.es/index.php/RFRM/article/view/RFRM0606220399A/10152

Freire-Medeiros, B \& Castro, C. (2007). A cidade e seus souvenires: o Rio de Janeiro para o turista ter. Revista Brasileira de Pesquisa em Turismo, 1(1), 34-53. Recuperado em 19 de agosto, 2014, de http://www.rbtur.org.br/rbtur/article/view/78/77

Gil, A.C. (2007). Como elaborar projetos de pesquisa. São Paulo: Atlas.

Gordon, B. (1986). The Souvenir: Messenger of The Extraordinary. Journal of Popular Culture, 20(3), 135-146.

Grupo Giordani Turismo. (2013). Case Giordani Turismo: Trem Maria Fumaça. Anais do Simpósio Nacional sobre Gestão Ambiental em Empreendimentos Turísticos, Bento 
Gonçalves. Recuperado em 02 de junho, 2014, de http://abesrs.org.br/ambientur/datadesk/palestras.php

Grupo Giordani Turismo. (2014). Fotos oficiais - Maria Fumaça. Recuperado em 15 de agosto, 2014, de http://www.giordaniturismo.com.br/galerias/ver/17

Horodyski, G. S., Manosso, F. C. \& Gândara, J. M. G. (2012). O consumo de souvenirs e a experiência turística em Curitiba (PR). Caderno Virtual de Turismo, 12(3), 323-342.

Recuperado em 31 de março de 2014, de http://www.ivt.coppe.ufrj.br/caderno/index.php?journal=caderno\&page=article\&op=view\&pa th $\% 5 \mathrm{~B} \% 5 \mathrm{D}=693 \&$ path $\% 5 \mathrm{~B} \% 5 \mathrm{D}=338$

Horodyski, G. S., Manosso, F. C. \& Gândara, J. M. G. (2013). Conceitos e abrangência do souvenir na dinâmica do espaço turístico. Revista Turismo Visão e Ação, 15(1), 130-143.

$\begin{array}{llllll}\text { Recuperado em } & 15 & \text { de } & \text { agosto, }\end{array}$ http://siaiweb06.univali.br/seer/index.php/rtva/article/view/4084/2494

Kotler, P.\& Armstrong, G. (2007). Princípios de marketing. São Paulo: Pearson Prentice Hall.

Las Casas, A. L. (2008). Administração de marketing: conceitos, planejamento e aplicações à realidade brasileira. São Paulo: Atlas.

Leite, A. L. S.; Fiates, G. G. S. \& Lima, M. A. (2013). Fatores condicionantes da vantagem competitiva nos postos de combustível de Florianópolis. REBRAE - Revista Brasileira de Estratégia. Curitiba, 6(1), 37-44. Recuperado em 04 de fevereiro, 2016, de http://www2.pucpr.br/reol/pb/index.php/rebrae?dd1=7665\&dd99=view\&dd98=pb

Lipovetsky, G. (2007). A felicidade paradoxal: ensaio sobre a sociedade do hiperconsumo. São Paulo: Companhia das letras.

Machado, P. S. \& Siqueira, E. D. (2008). Turismo, consumo e cultura: significados e usos ociais do suvenir em Petrópolis-RJ. Revista Contemporânea, 1(10), 2-18. Recuperado em 15 de agosto, 2014, de http://www.contemporanea.uerj.br/pdf/ed_10/contemporanea_n10_euler_david.pdf

Magalhães, M. F. \& Sampaio, R. (2007). Planejamento de marketing: conhecer, decidir, agir. São Paulo: Pearson Prentice Hall.

Middleton, V. T. C. (2002). Marketing de turismo: teoria e prática. Rio de Janeiro: Campus.

Petrocchi, M. (2004). Marketing para destinos turísticos. São Paulo: Futura.

Reis, J. R. (2008). "Lembrei-me de você": o consumo de souvenires atribuindo significado à viagem turística. Anais do $V$ Seminário da Associação Nacional de Pesquisa e de PósGraduação em Turismo, Belo Horizonte.

Salgueiro, V. (2002). Grand Tour: uma contribuição à história do viajar por prazer e por amor à cultura. Revista Brasileira de História, 22(44), 289-310. Recuperado em 15 de agosto, 
2014, de: $\quad<$ http://www.scielo.br/scielo.php?script=sci_arttext\&pid=S0102$01882002000200003 \& \operatorname{lng}=\mathrm{en} \& \mathrm{nrm}=\mathrm{iso}>$.

Shiraishi, G. (org). (2012). Pesquisa de marketing: bibliografia universitária. São Paulo: Pearson Prentice Hall.

Tachner, G. B. (2000). Lazer, cultura e consumo. Revista de Administração de Empresas, 40(4), 38-47. Recuperado em 15 de agosto, 2014, de http://rae.fgv.br/sites/rae.fgv.br/files/artigos/10.1590_S003475902000000400004.pdf

Torres, M. D. M. M., García, J. A. S. \& Pulido-Fernandéz, J. I. (2013). Cambio de paradigma en el marketing de destinos turísticos: el plan CMA Experience. Cultur: revista de cultura e turismo, 7(2), 4-32. Recuperado em 19 de agosto, 2014, de http://www.uesc.br/revistas/culturaeturismo/ano7-edicao2/1.pulido.pdf 